\title{
Percepção de medo da morte: avaliando sua relação com os valores humanos e bem-estar subjetivo
}

\author{
Percepción del miedo a la muerte: evaluando su \\ relación con los valores humanos y el bienestar \\ subjetivo
}

\section{Perception of fear of death: evaluating its relationship with human values and subjective well-being}

\author{
Ana Karla Silva Soares \\ ORCID ID: 0000-0001-5306-4073 \\ Universidade Federal do Mato Grosso do Sul, Brasil \\ Nataly da Cruz Serejo Barbosa \\ ORCID ID: 0000-0002-1675-1525 \\ Universidade Federal do Mato Grosso do Sul, Brasil \\ Hysla Magalhães de Moura \\ ORCID ID: 0000-0002-5866-5799 \\ Universidade do Estado do Rio de Janeiro, Brasil \\ Alessandro Teixeira Rezende \\ ORCID ID: 0000-0002-5381-2155 \\ Universidade Federal da Paraíba, Brasil \\ Autor referente: akssoares@gmail.com \\ Historia editorial \\ Recibido: 18/04/2020 \\ Aceptado: 19/10/2020
}

RESUMO:

O confronto com a finitude humana pode acarretar medo e incertezas. Este estudo avaliou em que medida e direção 0 medo da morte está relacionado com as prioridades valorativas e com o nível de bem-estar subjetivo dos indivíduos. Participaram desta pesquisa 430 pessoas com idade 
média de 27 anos ( $D P=8,34)$, as quais responderam aos seguintes instrumentos: Escala de Medo da Morte de Collett-Lester, Escala de Satisfação com a Vida, Escala de Afetos Positivos e Negativos, Questionário dos Valores Básicos e questões demográficas. Os resultados da correlação indicaram que o medo da morte, tanto de si quanto dos outros, relacionou-se significativamente com todas subfunções valorativas (exceto normativa no fator medo da própria morte), ao passo que com as variáveis de bem-estar subjetivo, identificou-se correlação apenas com afetos negativos. Ademais, a análise de regressão indicou que as subfunções realização e interativa e os afetos negativos explicaram significativamente tanto o medo da própria morte, quanto à dos outros.

Palavras-chave: Morte; bem-estar subjetivo; valores humanos.

\section{RESUMEN:}

La confrontación con la finitud humana a menudo causa miedo e incertidumbre. Este estudio evaluó el alcance y la dirección del miedo a la muerte en relación con las prioridades de valoración y el bienestar subjetivo de los individuos. 430 personas participaron en el presente estudio con una edad promedio de 27 años (DE = 8.34) que respondieron los siguientes instrumentos: Escala de miedo a la muerte de Collett-Lester, Escala de satisfacción con la vida, Escala de afecciones positivas y negativas, Cuestionario de valores básicos y preguntas demográficas. Los resultados de la correlación indicaron que el miedo a la muerte, tanto de sí mismos como de los demás, estaba significativamente relacionado con todas las subfunciones de valoración (excepto normativas en el factor miedo a la muerte propia), mientras que con las variables subjetivas de bienestar, se identificó una correlación solo con efectos negativos. Además, el análisis de regresión indicó que la realización y las subfunciones interactivas y los afectos negativos explicaron significativamente tanto el miedo a la muerte propia como a la de los demás.

Palabras clave: Muerte; bienestar subjetivo; valores humanos.

\section{ABSTRACT:}

The confrontation with human finitude leads to fear and uncertainty. This study evaluated the extent and direction of fear of death related to the valuation priorities and the subjective well-being of individuals. 430 people participated in the present study with an average age of 27 years $(S D=8.34)$. These responded to the following instruments: Collett-Lester Fear of Death Scale, Life Satisfaction Scale, Scale of Positive and Negative Affects, Basic Values Survey and demographic questions. The correlation results indicated that the fear of death, both for oneself and for others, was significantly related to all the evaluative subfunctions (except normative in the factor of fear of the self), whereas with the subjective wellbeing variables, correlation was identified only with negative effects. Furthermore, the regression analysis 
indicated that the realization and interactive subfunctions and negative affects significantly explained both the fear of death itself and that of others.

Keywords: Death; subjective well-being; humans values.

morte é, sem dúvida, uma das maiores inquietações do ser humano. O
confronto com a finitude, muitas vezes, é velado por medos e mitos, assim como pela incerteza do que virá e se virá. Pensar sobre o fim da existência pode suscitar discussões sobre a possibilidade de haver outra vida após o falecimento, por exemplo, no inferno ou no paraíso.

Assim, a concepção sobre a morte e a atitude do homem perante ela, tende a mudar conforme seu contexto histórico e cultural (Omena \& Funari, 2017). Na Idade Antiga os romanos já demonstravam medo de seus mortos e, por isso, realizavam ritos para impedir "seu retorno". Enquanto que a Idade Média foi marcada pela diversidade de formas pelas quais cada cultura personificava a morte e elaborava cerimônias e ritos para lidar com a mesma (Morais, 2012).

Já na contemporaneidade, com a evolução da medicina, a morte deixou de ocorrer nas residências e passou para os hospitais, fazendo-se presente no cotidiano dos profissionais da saúde. A partir disso, a morte deixou de ser considerada como um acontecimento esperado, natural e compartilhado, e passou a ser concebida como sendo institucionalizada (Massaroni \& Barbosa, 2016). Ao que parece, a alteração da forma de enfrentamento da morte, de algo natural para ser associada à ideia do possível de domínio de conhecimento, é um dos elementos que influenciou na dificuldade em se falar sobre a temática (Massaroni \& Barbosa, 2016).

Há de se dizer que o medo da morte engloba alguns componentes, como, por exemplo, a angústia de deixar essa vida, a incerteza em relação à existência de vida pós-morte e o temor do sofrimento no momento da morte (Massaroni \& Barbosa, 
2016). Ao que parece, a compreensão da maneira como cada pessoa lida com a percepção ou conceituação de morte pode favorecer o entendimento de outras esferas de sua vida, tais como, sua influência em dimensões relacionadas à saúde geral, especificamente, no que cerne ao construto de bem-estar subjetivo (Palgi et al., 2010). Assim, confia-se que esta última variável tenha importante papel para compreender as implicações que o medo da morte pode exercer na vida das pessoas.

Segundo Diener, Oishi e Lucas (2015), o bem-estar subjetivo é definido como uma temática que contempla diferentes fatores que visam, conjuntamente, compreender a avaliação geral, cognitiva e afetiva que o indivíduo faz de sua própria vida. Este construto é mensurado a partir de duas dimensões gerais: a) a cognitiva, comumente verificada por meio do nível de satisfação com a vida, e b) a afetiva, identificada através do grau de afetos positivos e negativos apresentados (Jebb, Morrison, Tay, \& Diener, 2020).

Nesta mesma direção, visando identificar variáveis correlatas ao medo da morte, considerando as individualidades e as especificidades de cada cultura, identifica-se atrelada a mesma questões filosóficas e existenciais da vida humana, baseadas em crenças, ritos, mitos e valores humanos (Oliveira Júnior et al., 2018). Ressalta-se que este último construto é comumente empregado na literatura como sendo preditor de diferentes aspectos atitudinais e comportamentais (Gouveia, 2016), dentre os quais pode-se mencionar sua relação com a temática da morte (Morais, 2012).

É nesse cenário que o presente estudo se fundamenta na compreensão da percepção dos indivíduos acerca do medo da morte tendo como objetivo geral avaliar em que medida e direção a percepção do medo da morte está relacionada e pode ser explicada pelas prioridades valorativas e pelos níveis de bem-estar subjetivo dos indivíduos. Especificamente, pretende-se avaliar a adequação psicométrica de uma medida utilizada nesta pesquisa para mensurar o temor da finitude humana, as correlações entre as variáveis e, por fim, o papel preditor dos valores humanos e do 
bem-estar subjetivo em relação a percepção de medo da morte.

\section{Medo da morte}

O medo da morte consiste em uma reação provocada por situações que colocam a vida ou sua integridade em risco de morte (Wong et al., 1994). Ademais, pode ser compreendido como as interpretações que as pessoas fazem quanto ao processo de perder sua existência, enfrentar o desconhecido e quanto a dúvida sobre a possibilidade de haver vida após a finitude, com a literatura indicando a presença deste temor em todas as culturas (Simkin \& Quintero, 2017).

Deste modo, os fenômenos relacionados à ansiedade sobre morrer (processo) e a morte (produto) necessitam de ampla discussão, análise e interpretação para que possam ser melhor compreendidos e aceitos (Oliveira Júnior et al., 2018). Diante disto, identifica-se a necessidade de ferramentas para mensurar este construto, dentre as quais destaca-se a Escala de Medo da Morte de Collett-Lester (Collett \& Lester, 1969). Collett e Lester (1969) concebem o temor da morte como sendo composto por quatro dimensões: a) medo da própria morte, que implica o fim como pessoa e da própria existência; b) medo da morte de outras pessoas, referindo-se a hipótese da morte de alguém querido; c) medo do processo da própria morte, remetendo a um percurso de sofrimento que conduz à morte, como, por exemplo, associado à doença degenerativa e/ou à morte lenta; d) medo do processo de morrer de outras pessoas, considerando a possibilidade de doença dolorosa e morte lenta de uma pessoa estimada.

A nível internacional são identificados estudos, como por exemplo, o de Simkin e Quintero (2017) na Argentina e Mondragon-Sanchez, Landeros-Olvera, \& PérezNoriega (2020) no México, direcionados a adaptação da medida. Simkin e Quintero (2017) identificaram uma estrutura diferente da original (quatro fatores, Collett \& Lester, 1969) em uma amostra de 150 estudantes universitários, sendo a mesma constituída por dois fatores, denominados de medo da própria morte $(\alpha=0,62)$ e medo 
da morte dos outros $(\alpha=0,73)$.

Enquanto que na pesquisa de Mondragon-Sanchez et al (2020), com 368 estudantes do curso de enfermagem, corroborou-se a estrutura de quatro fatores semelhante a original (medo da própria morte, medo da morte de outras pessoas, medo do processo da própria morte e medo do processo de morrer de outras pessoas, com os respectivos alfas de Cronbach: $0,87,0,89,0,88,0,89$ ).

No contexto brasileiro, identificou-se apenas a pesquisa de Oliveira Júnior et al. (2018) voltada para tradução da Escala de Medo da Morte de Collett-Lester a realidade brasileira, demonstrando o interesse de pesquisadores em mensurar esse fenômeno no Brasil. Contudo, os autores dedicaram-se exclusivamente a apresentação dos procedimentos de tradução do instrumento, não sendo analisados aspectos relacionados as evidências de adequação psicométrica da medida (e.g., validade e precisão), atividade esta desenvolvida no presente estudo. Efetivamente, instrumentos que permitem avaliar o temor da morte possibilitam ampliar as discussões sobre possíveis implicações que a mesma apresenta na saúde e no bem-estar das pessoas a partir, por exemplo, da análise de sua relação para com o bem-estar subjetivo.

\section{Bem-estar subjetivo}

O bem-estar subjetivo (BES) diz respeito à satisfação que cada sujeito confere a diferentes áreas de sua vida (Jebb et al., 2020), sendo o descritor "subjetivo" empregado para definir e limitar o escopo do construto, ou seja, dando importância as avaliações da qualidade da vida do indivíduo a partir de sua própria perspectiva. Assim, o BES tem por finalidade compreender como e o porquê as pessoas experimentam suas vidas de diversas maneiras, incluindo suas avaliações a) cognitivas (comporta o âmbito da satisfação com a vida) e b) emocionais (composta pelos afetos positivos e afetos negativos) (Diener, Oishi, \& Lucas, 2018). Nesta pesquisa, o bem-estar subjetivo será contemplado por meio da avaliação das 
suas duas dimensões (cognitiva e emocional), no qual o aspecto cognitivo será mensurado por meio da avaliação dos níveis de satisfação com a vida (Karaca, Karakoc, Bingol, Eren, \& Andsoy, 2016), que envolve a avaliação racional da própria satisfação com as experiências vivenciadas pelo indivíduo, tratando do julgamento cognitivo consciente da vida empregando critérios pessoais. Já o aspecto emocional contempla afetos positivos e negativos pautando-se na intensidade e na frequência com que as pessoas vivenciam emoções, englobando a relação entre os sentimentos agradáveis (e.g., alegria) e desagradáveis (e.g. raiva) (Diener et al., 2018).

Nesta direção, partindo-se da proposta de manter o foco trazido pela Psicologia Positiva de ampliar ou mesmo manter o interesse em elementos norteadores de comportamentos e atitudes humanas positivas (Gouveia, 2013), a seguir, serão apresentadas definições de um construto amplamente contemplado na Psicologia Social e que tem por direcionamento a análise das bases axiológicas e da natureza benevolente dos seres humanos, denominado de valores humanos.

\section{Teoria Funcionalista dos valores humanos}

Os valores humanos podem ser entendidos como sendo aspectos psicológicos capazes de influenciar em uma ampla variedade de contextos, atitudes e comportamentos, inclusive na maneira pela qual as pessoas lidam com a morte (Gouveia, Milfont, \& Guerra, 2014; Morais, Nunes, Cavalcanti, Soares, \& Gouveia, 2016). Destaca-se que na tentativa de entender este construto, a decorrente pesquisa adotou a Teoria Funcionalista dos Valores Humanos.

Esta abordagem teórica (Gouveia, 2013) retrata a natureza benevolente do ser humano, apresentando um modelo teórico compreendido por dois eixos principais, a saber: a) os valores servem como padrões que guiam os comportamentos (tipo orientação); e b) representam cognitivamente as necessidades humanas (tipo de motivador) (Gouveia, 2013; Gouveia et al., 2014). Do cruzamento dessas funções (tipo 
de orientação e de motivador) são geradas seis subfunções específicas dos valores, com três modalidades de orientação (social, central e pessoal) e duas de motivadores (materialista e humanitário).

De acordo com a Teoria Funcionalista dos Valores Humanos pessoas compatíveis com os valores sociais priorizam a convivência social, relacionam-se com os interesses coletivos e com a busca por aceitação e integração ao grupo. Esta prioridade valorativa está, então, subdividida nas seguintes subfunções: a) interativa, representando as necessidades de pertença, amor e afiliação, sendo seus três valores definidores a afetividade, a convivência e o apoio social (Gouveia, 2013); e b) normativa, onde a obediência à autoridade é fundamental e conota a importância de preservar a cultura e as normas convencionais (Gouveia, 2016). Os três valores descritores desta subfunção são tradição, obediência e religiosidade (Gouveia, 2013). Indivíduos que priorizam valores pessoais buscam alcançar metas pessoais e condições propícias para atingir seus objetivos (Gouveia, 2016). Esta prioridade axiológica é caracterizada pelas subfunções a) realização e b) experimentação. A primeira mencionada focaliza nas realizações materiais. Os descritores desta subfunção são: êxito, prestígio e poder (Gouveia, 2013). Em contrapartida, a subfunção experimentação refere-se à sexualidade, prazer e emoção. Indivíduos que adotam tais valores são menos prováveis de conformarem-se com as regras sociais (Gouveia, 2013, 2016).

Já as pessoas que primam pelos valores centrais são aquelas que possuem interesses mistos, localizados entre os valores pessoais e sociais. Esta prioridade valorativa é composta pelas seguintes subfunções: a) existência, refere-se às necessidades fisiológicas mais básicas. Os descritores desta subfunção são: saúde, sobrevivência e estabilidade emocional (Gouveia, 2013); e b) suprapessoal, a qual conota as necessidades estética e de cognição (Gouveia, 2013) e auxiliam na organização e categorização do mundo de modo consistente (Gouveia, 2016). Os 
descritores desta subfunção são: conhecimento, maturidade e beleza.

Em um estudo realizado por Marques, Silva e Céu-Taveira (2017) verificou-se que os valores do tipo pessoal, central e social predisseram a satisfação com a vida, tendo a subfunção experimentação maior poder de explicação deste último construto mencionado. Pode-se mencionar ainda a pesquisa desenvolvida por Morais (2012) com estudantes e profissionais da medicina, a qual avaliou o papel dos valores em suas análises do significado de morte. Seus resultados indicaram que a percepção dos atributos de uma morte digna pareceu se fundamentar mais em princípios valorativos, que acentuam o motivador humanitário, representado pelas subfunções interativa e suprapessoal.

Tendo em vista o panorama exposto, realizaram-se buscas nas bases de dados (Abril - 2020) SciELO (Scientific Electronic Library Online), PePSIC, Index Psi e PsycINFO. Nas três primeiras, os termos de busca com operadores boleanos foram "valores" AND "morte" AND "bem-estar". Já na última foram utilizados os termos "values" AND "death" AND "well-being". Como o objetivo foi identificar estudos que avaliassem as variáveis em conjunto, optou-se por não delimitar na busca o período de publicação. Em tal levantamento não foi encontrado nenhum estudo empírico que tratasse da relação entre essas três variáveis. Confia-se, então, ser de suma importância o desenvolvimento de pesquisas de natureza empírica que relacionem estes fatores, a fim de identificar em que medida e direção o medo da morte está relacionado aos níveis de bem-estar subjetivo e as prioridades valorativas das pessoas, justificando, assim, a decorrente pesquisa.

\section{Método}

\section{Participantes}

Participaram do presente estudo 430 pessoas com idade média de 27 anos $(D P=$ 8,34; variando de 18 a 59 anos), sendo a maioria do sexo feminino (80\%), solteira 
$(73,7 \%)$, com ensino superior incompleto $(52,2 \%)$ e que relataram ter perdido algum ente querido $(73,2 \%)$ há, em média, três anos ( $D P=5,04$ anos $)$.

Instrumentos

Os participantes responderam aos seguintes instrumentos:

Escala de Medo da Morte de Collett-Lester (EMMCL). Esta medida foi originalmente elaborada por Collett e Lester (1969), traduzida para o português por Oliveira Júnior et al. (2018) e adaptada e validada para o contexto brasileiro no presente estudo. A mesma é constituída por 28 itens, respondidos em uma escala do tipo Likert de cinco pontos, variando de 1 (nada) a 5 (muito).

Questionário dos Valores Básicos (QVB, Gouveia, 2013). Conta com 18 itens ou valores específicos. Estes valores são distribuídos equitativamente nas seis subfunções valorativas previamente descritas: experimentação, realização, existência, suprapessoal, interativa e normativa. Com o fim de respondê-los, o participante deve ler cada item com atenção e avaliar sua importância como um princípio-guia na sua vida, utilizando-se de uma escala do tipo Likert de sete pontos, variando de 1 (Totalmente não importante) a 7 (Totalmente importante). Este instrumento apresenta índices de confiabilidade aceitáveis, variando de 0,53 a 0,60 (Gouveia et al., 2014).

Escala de Satisfação com a Vida. Elaborada originalmente por Diener, Emmons, Larsen e Griffin (1985), esta medida avalia o nível de satisfação com a vida das pessoas. Compõe-se de cinco itens, respondidos a partir de uma escala do tipo Likert de sete pontos, variando entre 1 (Discordo Totalmente) a 7 (Concordo Totalmente). Este instrumento apresentou indicadores adequados de validade (fatorial) e precisão $(\alpha=0,87)$.

Escala de Afetos Positivos e Negativos (EAPN-10). Esta escala avalia a valência dos afetos. É formada por dez adjetivos, sendo cinco positivos (feliz, alegre, satisfeito, otimista e divertido) e cinco negativos (deprimido, preocupado, frustrado, raivoso e infeliz). O instrumento avalia quanto o participante tem experimentado cada um destes 
afetos nos últimos dias. Os itens são respondidos em uma escala do tipo Likert de sete pontos, variando de 1 (Nada) a 7 (Extremamente). Esta medida apresenta indicadores adequados de validade (fatorial) e precisão: afetos positivos $(\alpha=0,82)$ e afetos negativos $(\alpha=0,81)$ (Gouveia et al., 2019).

Questionário demográfico. Tem como objetivo caracterizar o perfil demográfico dos participantes do estudo, apresentando perguntas relativas à idade, sexo, estado civil, se já perdeu algum ente querido, e em caso afirmativo, há quanto tempo.

\section{Procedimento}

Os dados foram coletados on-line. Solicitou-se a participação das pessoas por meio de redes sociais (e.g., Facebook e Instagram), garantindo o caráter anônimo e a natureza voluntária da participação. Todos concordaram com o Termo de Consentimento Livre e Esclarecido, presente na primeira página do questionário, e tiveram acesso a uma via do mesmo. Este estudo contou com aprovação do Comitê de Ética em Pesquisa (CAAE: 01354918.5.0000.0021), seguindo todos os preceitos éticos que envolvem pesquisas com seres humanos que é regulamentado pela Resolução 510/16 do Conselho Nacional de Saúde.

\section{Análise dos dados}

Para análise e tabulação dos dados quantitativos foi empregado o software Statistical Package for the Social Science (SPSS, versão 21), o qual permitiu calcular estatísticas descritivas, análise de correlação $r$ de Pearson e regressão linear (método stepwise). O software Factor (versão 10.10.02) foi utilizado para averiguar as evidências de adequação psicométrica (Minimum Rank Factor Analysis, rotação promin), método de retenção fatorial - Análise paralela/Optimal implementation). A consistência interna dos fatores foi avaliada por meio do índice ômega de Mcdonald ( $\omega)$, obtido por meio do programa $\mathrm{R}$ (R Development Core Team, 2011), utilizando o pacote semTools. 


\section{Resultados}

\section{Análise fatorial exploratória da EMMCL}

Inicialmente, o Kaiser-Meyer-Olkin $(\mathrm{KMO}=0,90)$ e o Teste de Esfericidade de Bartlett $\left[\square^{2}(378)=4822,0 p<0,001\right]$ demonstraram a adequação da matriz de correlações policóricas e atestaram a pertinência de se proceder uma Análise Fatorial Exploratória (AFE) que tem por finalidade atestar a adequação e verificar os parâmetros psicométricos da EMMCL. Uma análise preliminar revelou a presença de dois fatores (análise paralela baseada no método Minimum Rank Factor Analysis) e os achados são reportados na Tabela 1 .

Tabela 1

Estrutura fatorial da Escala de Medo da Morte de Collett-Lester ( $n=430)$

\begin{tabular}{llll}
\hline & Morrer sozinho. & Item & II \\
2 & A vida curta. & 0,04 & $\mathbf{0 , 6 4}$ \\
3 & Todas as coisas que você perderá quando morrer. & $-0,07$ & $\mathbf{0 , 7 0}$ \\
4 & Morrer Jovem. & $-0,17$ & $\mathbf{0 , 8 1}$ \\
5 & Como será estar morto. & $-0,13$ & $\mathbf{0 , 7 5}$ \\
6 & Não ser capaz de pensar ou sentir algo de novo. & $-0,07$ & $\mathbf{0 , 7 7}$ \\
7 & A desintegração do corpo após a morte. & $-0,21$ & $\mathbf{0 , 8 6}$ \\
8 & A degeneração física que se associa o processo de & $-0,01$ & $\mathbf{0 , 6 2}$ \\
& morrer. & & \\
9 & A dor do processo de morrer. & 0,13 & $\mathbf{0 , 5 1}$ \\
10 & A degeneração mental do envelhecimento. & 0,10 & $\mathbf{0 , 5 1}$ \\
11 & Perda de capacidades durante o processo de morrer. & 0,22 & $\mathbf{0 , 4 7}$ \\
\hline
\end{tabular}


Tabela 1. Estrutura fatorial da Escala de Medo da Morte de Collett-Lester $(n=430)$ (Continuação)

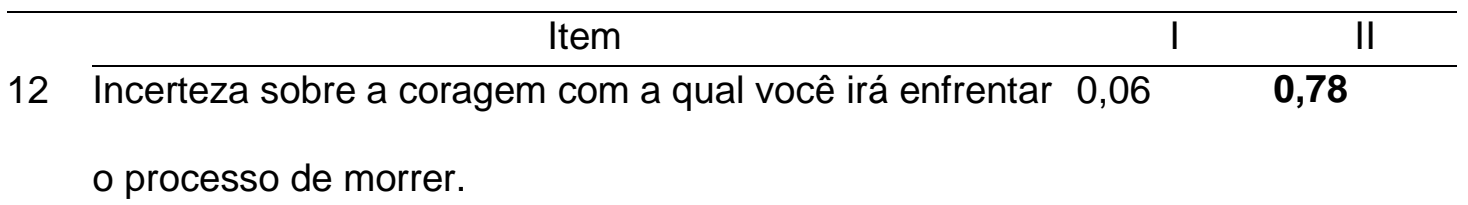

13 Sua falta de controle sobre o processo de morrer.

14 A possibilidade de morrer em um hospital longe de

$0,23 \quad \mathbf{0 , 5 0}$
amigos e familiares.

15 A perda de um ente querido.

$\mathbf{0 , 7 8} \quad-0,04$

16 Ter que ver seu cadáver.

$\mathbf{0 , 6 5}-0,02$

17 Não conseguir se comunicar com essa pessoa

$\mathbf{0 , 7 7} \quad-0,01$
novamente.

18 Lamentar não ter ficado mais com ela quando ela ainda estava viva.

19 Envelhecer sozinho, sem a pessoa querido.

20 Sentir-se culpado pelo alívio causado por sua morte.

21 Sentir-se sozinho(a).

22 Ter que estar com alguém que está morrendo.

$\mathbf{0 , 7 5} \quad-0,13$

23 Ter que estar com alguém que queira falar sobre a morte $\mathbf{0 , 3 2}$ com você.

24 Ver seu sofrimento. $\mathbf{0 , 8 7}-0,16$

25 Observar a degeneração do seu corpo. $\mathbf{0 , 8 8} \quad-0,15$

26 Não saber administrar sua dor diante da perda de uma $\mathbf{0 , 7 5} \quad 0,10$ pessoa amada.

27 Assistir à deterioração de suas faculdades mentais.

$\mathbf{0 , 7 7}-0,06$


Tabela 1. Estrutura fatorial da Escala de Medo da Morte de Collett-Lester $(n=430)$ (Continuação)

\begin{tabular}{lrc}
\hline \multicolumn{1}{c}{ Item } & I & II \\
\cline { 2 - 4 } Saber que algum dia você também viverá essa & 0,34 & 0,54 \\
experiência. & 13 & 14 \\
Número de itens & $49 \%$ & $11 \%$ \\
Variância explicada & 0,90 & 0,89 \\
Índice de fidedignidade $(\Omega)$ & &
\end{tabular}

Nota: I = Fator Medo da Morte dos Outros; II = Fator Medo da Própria Morte

Conforme a Tabela 1, os dois fatores encontrados explicaram conjuntamente $61,40 \%$ da variância total. O primeiro fator reuniu nove itens com cargas fatoriais variando de 0,48 (Item 20. Sentir-se culpado pelo alívio causado por sua morte) a 0,79 (Item 25. Observar a degeneração do seu corpo). Ele foi denominado como "medo da morte dos outros", apresentando índice de fidedignidade de 0,87. O segundo fator também reuniu nove itens com cargas fatoriais variando de 0,51 (Item 10. A degeneração mental do envelhecimento) a 0,74 (Item 7. A desintegração do corpo após a morte). Este fator foi nomeado como "medo da própria morte", apresentando índice de fidedignidade de 0,83. Foi utilizado como critério para definir a pertença do item ao fator, saturação igual ou superior a 0,30 , sendo eliminados os itens com valores inferiores a este nos dois fatores.

Correlatos do medo da morte, valores humanos e bem-estar subjetivo Inicialmente, optou-se por conhecer em que medida e direção as subfunções valorativas e o bem-estar subjetivo se correlacionam com os dois fatores de medo da morte. Os resultados são apresentados na Tabela 2. 
Tabela 2

Correlatos do medo da morte, valores humanos e bem-estar subjetivo $(N=430)$

\begin{tabular}{ccc}
\hline & Medo da Própria Morte & Medo da Morte dos Outros \\
\cline { 2 - 3 } Experimentação & $0,26^{* *}$ & $0,21^{* *}$ \\
Suprapessoal & $0,32^{* *}$ & $0,28^{* *}$ \\
Existência & $0,24^{* *}$ & $0,16^{* *}$ \\
Interativa & $0,29^{* *}$ & $0,26^{* *}$ \\
Normativa & $0,30^{* *}$ & $0,25^{\star *}$ \\
Satisfação com a vida & 0,08 & $0,13^{*}$ \\
Afetos positivos & $-0,03$ & 0,02 \\
Afetos negativos & $-0,08$ & $-0,08$ \\
\hline
\end{tabular}

Nota: ${ }^{* *} p<0,001 ;{ }^{*} p<0,05$

Visando identificar o poder preditivo das subfunções valorativas e dos afetos negativos na explicação dos fatores de medo da morte, foram efetuadas duas análises de regressão linear múltipla. Nessa oportunidade, a fim de evitar o efeito de multicolinearidade, optou-se pelo método de regressão stepwise, sendo a mesma avaliada e descartada em virtude dos valores de FIV (Média própriamorte $=1,18$; Média $_{\text {morteoutros }}=1,18$ ) próximos a 1 e Tolerâncias acima de 0,20. Especificamente, efetuaram-se duas análises tendo em conta cada um dos dois fatores de medo da morte (própria e dos outros) como variável-critério, e as subfunções valorativas e os afetos negativos como variáveis antecedentes (preditoras). Os resultados são apresentados na Tabela 3 a seguir. 
Tabela 3

Regressão Linear (stepwise) dos fatores de medo da morte (valores humanos e afetos como preditores)

\begin{tabular}{|c|c|c|c|c|c|c|c|c|}
\hline & Preditores & $\mathrm{R}$ & $\begin{array}{c}\mathrm{R}^{2} \\
\text { ajustado }\end{array}$ & $F$ & $B$ & Beta & $t$ & FIV (Tol) \\
\hline & Realização & 0,32 & 0,10 & $\begin{array}{c}F(428)= \\
48,92\end{array}$ & 0,15 & 0,20 & $4,05^{\star}$ & $\begin{array}{c}1,27 \\
(0,78)\end{array}$ \\
\hline \multirow[t]{2}{*}{1} & $\begin{array}{c}\text { Afetos } \\
\text { negativos }\end{array}$ & 0,41 & 0,16 & $\begin{array}{c}F(427)= \\
32,82\end{array}$ & 0,18 & 0,26 & $5,93^{*}$ & $\begin{array}{c}1,01 \\
(0,98)\end{array}$ \\
\hline & Interativa & 0,45 & 0,19 & $\begin{array}{c}F(426)= \\
17,04\end{array}$ & 0,15 & 0,20 & $4,13^{*}$ & $\begin{array}{c}1,28 \\
(0,80)\end{array}$ \\
\hline \multirow{3}{*}{2} & $\begin{array}{c}\text { Afetos } \\
\text { negativos }\end{array}$ & 0,34 & 0,11 & $\begin{array}{c}F(428)= \\
55,25\end{array}$ & 0,21 & 0,31 & $7,12^{*}$ & $\begin{array}{c}1,01 \\
(0,98)\end{array}$ \\
\hline & Realização & 0,42 & 0,17 & $\begin{array}{c}F(427)= \\
31,22\end{array}$ & 0,12 & 0,17 & $3,54^{*}$ & $\begin{array}{c}1,27 \\
(0,78)\end{array}$ \\
\hline & Interativa & 0,44 & 0,19 & $\begin{array}{c}F(426)= \\
21,09\end{array}$ & 0,11 & 0,16 & $3,33^{*}$ & $\begin{array}{c}1,26 \\
(0,80)\end{array}$ \\
\hline
\end{tabular}

Notas. 1 = Medo da Própria Morte; 2 = Medo da Morte dos Outros; ${ }^{*} p<0,001$. FIV = Fator de inflação da variância; Tol - Tolerância

Quanto ao medo da própria morte, foram identificados como principais preditores as subfunções realização, interativa e os afetos negativos, os quais explicaram conjuntamente $17 \%$ da variância total ( $R^{2}$ ajustado). Ressalta-se a relevância da subfunção realização $\left[R^{2}\right.$ ajustado $\left.=0,10 ; F(428)=48,92 ; p=0,001\right]$ como a mais importante do modelo, visto sua contribuição de $10 \%$ na explicação total do medo da própria morte. No que se refere ao medo da morte dos outros, os melhores preditores foram os afetos negativos, as subfunções realização e interativa, que explicaram conjuntamente $19 \%$ da variância total ( $R^{2}$ ajustado). 


\section{Discussão}

O presente estudo buscou conhecer em que medida os valores humanos e o bemestar-subjetivo se associam com o medo da morte tomando como base a Teoria Funcionalista dos Valores Humanos (Gouveia, 2013). Estima-se que os objetivos tenham sido alcançados.

No que diz respeito aos achados da validação inicial da medida, buscou-se reunir evidências de adequação psicométrica da EMMCL no contexto brasileiro. Para tanto, avaliou-se seus parâmetros de validade e precisão. Como observado, a estrutura bifatorial identificada não condiz com a da medida original, no qual identificou quatro fatores (Collett \& Lester, 1969). Contudo, é semelhante a identificada em adaptações a outros contextos, a exemplo do estudo realizado por Simkin e Quitero (2017) na Argentina. Ademais, destaca-se que os indicadores de validade (fatorial) e consistência interna verificados no contexto brasileiro sugerem a adequação da medida, suportado tanto pelas cargas fatorais superiores ao sugerido na literatura, quanto pela coerência semântica e sua distribuição. Deste modo, confia-se que a EMMCL apresenta evidências de adequação psicométrica, podendo então ser empregada no Brasil para conhecer os correlatos do medo da morte.

No que diz respeito aos principais achados de correlação, foi observada uma correlação positiva e significativa entre o medo da morte dos outros e o medo da própria morte e todas as subfunções valorativas, excetuando a normativa no fator medo da própria morte. De acordo com Wong et al. (1994), o medo da morte consiste em uma reação provocada por situações que colocam a vida ou a integridade em risco de morte. Nessa perspectiva, a correlação significativa e positiva entre medo da própria morte com a subfunção valorativa experimentação tem sua explicação pautada no fato de que as pessoas que endossam estes valores tendem a buscar incessantemente por satisfação. Assim, estes indivíduos almejam aproveitar ao máximo de suas vidas. 
Ademais, esta prioridade axiológica (experimentação) é frequentemente priorizada por jovens adultos, faixa etária base desta pesquisa. Em geral, nesta idade, os indivíduos estão mais expostos a situações de risco (e.g., violência, comportamento antissocial e delitivo; Jara, Casas, \& Ortega-Ruiz, 2017), culminando em maior exposição à ambiente em que seja possível temer por suas vidas. De maneira similar, o fator "medo da morte dos outros" também se correlacionou com os valores de experimentação, possivelmente, em virtude da natureza idealista desta subfunção, segundo a qual é caracterizada por pessoas que defendem a igualdade entre as relações interpessoais e se preocupam com o futuro das novas gerações, gerando, assim, um temor de perder outras pessoas (Gouveia, 2016).

A subfunção realização (poder, prestígio e êxito) se relacionou com ambos os fatores de medo da morte, sendo característica de pessoas que priorizam realizações materiais, como observado no estudo de Gouveia et al. (2014). Esse achado era esperado tendo em vista que os indivíduos temem a própria morte em virtude da possibilidade de perder seus feitos e conquistas. Da mesma maneira, hipotetiza-se que as pessoas possuem receio da morte de outras pessoas haja vista a possibilidade desta situação impactar de alguma maneira em suas conquistas, ou mesmo, por almejar que existam pessoas que apreciem suas realizações, especialmente em se tratando dos indivíduos com quem mantêm laços sociais e familiares mais íntimos. Verificou-se também a relação positiva entre o medo da própria morte e da morte dos outros e a subfunção interativa (afetividade, convivência e apoio social), uma vez que indivíduos que priorizam esse valor tendem a ter uma necessidade maior de pertença, amor e filiação (Gouveia, 2013), assim, a morte poderia conotar a perda destes vínculos afetivos. Corroborando com esta perspectiva, pode-se mencionar o estudo desenvolvimento por Coelho, Gouveia, Fonsêca, Araújo e Vilar (2018). Nesta pesquisa foi possível verificar que a falta de relacionamentos mais íntimos na vida de um indivíduo apresenta-se vinculada a uma maior necessidade de pertença, uma vez que 
os relacionamentos constituem uma motivação da vida humana e, consequentemente, impactam no medo da finitude da vida.

Quanto à relação positiva entre o medo da morte dos outros e os valores normativos, possivelmente a natureza social desta subfunção (Gouveia, 2013; Gouveia et al., 2014) auxilie na compreensão deste achado, visto que consistem em valores cuja essência pauta-se na preocupação que o indivíduo possui com a comunidade. Diferentemente dos resultados visualizados entre estes valores e o fator medo da própria morte, em que não se identificou relação, provavelmente em detrimento do temor da própria finitude não envolver diretamente preocupações quanto ao atendimento de normais sociais.

No que tange aos valores centrais (existência e suprapessoal), identificou-se que o medo da própria morte e da morte dos outros se correlacionaram com ambas as subfunções. Estes achados seguem na direção da definição de cada conjunto de valores, já que indivíduos orientados por valores de existência buscam assegurar suas condições fisiológicas básicas, visando alcançar saúde, estabilidade e sobrevivência (Mariano, Medeiros, Gouveia, Sales, \& Nascimento, 2018). No caso dos valores suprapessoais, estes são endossados por pessoas que pensam de maneira mais ampla, buscando atender necessidades cognitivas e estéticas (Gouveia, 2013), aspectos estes que são perdidos durante o processo de morrer.

O bem-estar subjetivo, avaliado em suas duas dimensões cognitiva e afetiva (Karaca et al., 2016), só obteve correlação entre afetos negativos e o medo da morte (própria e dos outros). A morte, desde os primórdios, está vinculada às questões sombrias da existência humana (Morais, 2012). Nesse sentido, fica evidente que quanto maior o medo da morte mais se vivencia afetos negativos em relação à mesma. Segundo Massaroni e Barbosa (2016), o medo da morte engloba componentes como angústia, incertezas, ansiedade e temor do sofrimento no momento da morte. Estes achados corroboram também para a ausência de correlação significativa entre o medo da morte 
(própria e dos outros) com os aspectos positivos do bem-estar subjetivo, especificamente, a satisfação com a vida e os afetos positivos.

Visando ampliar o conhecimento quanto à relação das variáveis em análise, após identificar seus correlatos, buscou-se analisar quais elementos funcionariam como preditores do medo da morte (própria e dos outros). Especificamente, identificou-se que os valores e o bem-estar subjetivo predizem medo da própria morte apenas por meio das subfunções valorativas de realização e interativa, juntamente com afetos negativos.

Contudo, é relevante destacar que apesar dos achados serem significativos, o percentual de explicação das variáveis para com os fatores da escala de medo da morte não é elevado, sugerindo a necessidade de ampliar as análises incluindo outros grupos amostrais e construtos além dos contemplados nesta pesquisa. Assim, deve-se ponderar a capacidade das variáveis ora utilizadas de explicar amplamente a natureza do medo da morte, fenômeno complexo, que envolve características a níveis individuais (e.g., personalidade, crenças, religiosidade), culturais (e.g., significado da morte predominante da cultura) e situacionais (e.g., experiências de vida).

Estes achados reforçam a importância que a busca pela realização, a preocupação com os outros e a presença dos afetos negativos exercem na percepção que as pessoas possuem do medo de morrer e do temor da morte de outras pessoas.

Apesar das importantes contribuições que esta pesquisa proporcionou, a mesma não está livre de limitações. A respeito destas pode-se citar: a) a natureza da amostra, por não ter distribuição probabilística (conveniência) inviabiliza a generalização dos resultados para outros contextos; b) o emprego de medidas de autorrelato, isto é, do tipo "lápis e papel", implicando em algumas desvantagens já que o participante pode falsear suas respostas, diferindo-as da realidade ou tê-las enviesada devido à desejabilidade social, principalmente quando o tema é considerado indesejável socialmente, como é o caso de temáticas relacionadas à morte; c) houve 
homogeneidade da amostra no que se refere ao alcance geográfico da pesquisa, pois não se contou com participantes de todas as regiões geopolíticas do Brasil.

Por fim, ressalte-se que a literatura sobre a temática do medo da morte é escassa, principalmente ao avaliar o construto de forma empírica. Neste sentido, há de se destacar que não foi encontrado instrumentos psicométricos validados para o contexto brasileiro, de modo que o presente estudo pode contribuir com o preenchimento desta lacuna ao validar uma medida para mensurar o temor da finitude humana. No que se refere a estudos futuros, sugere-se pesquisas direcionadas a comprovar a estrutura fatorial encontrada no decorrente estudo, a partir da realização de uma análise fatorial confirmatória.

\section{Referências}

Coelho, G. L. H., Gouveia, V. V., Fonsêca, P. N., Araújo, R. C. R, \& Vilar, R. (2018). Escala de necessidade de pertença: evidências de qualidade psicométrica. Psico-USF, 23, 139-150. doi: https://dx.doi.org/10.1590/1413-82712018230112

Collett, L., \& Lester, D. (1969). The fear of death end the fear of dying. The Journal of Psychology: Interdisciplinary and Applied, 72, 179-181. doi: https://doi.org/10.1080/00223980.1969.10543496

Diener, E., Emmons, R. A., Larsen, R. J., \& Griffin, S. (1985). The satisfaction with life scale. Journal of Personality Assessment, 49, 71-75. doi: https://doi.org/10.1207/s15327752jpa4901_13

Diener, E., Lucas, R. E., \& Oishi, S. (2018). Advances and open questions in the science of subjective well-being. Collabra: Psychology, 4, 01-49. doi: http://doi.org/10.1525/collabra.115

Diener, E., Oishi, S., \& Lucas, R. E. (2015). National accounts of subjective well- being. American Psychologist, 70, 234-242. doi: http://dx.doi.org/10.1037/a0038899 
Gouveia, V. V. (2013). Teoria funcionalista dos valores humanos: fundamentos, aplicações e perspectivas. São Paulo: Casa do Psicólogo.

Gouveia, V. V. (2016). Introdução à Teoria Funcionalista dos Valores. In V. V. Gouveia (Ed.), Teoria funcionalista dos valores humanos: áreas de estudo e aplicações. São Paulo: Vetor.

Gouveia, V. V., Milfont, T. L., \& Guerra, V. M. (2014). Functional theory of human values: testing its content and structure hypotheses. Personality and Individual Differences, 60, 41-47. doi: https://doi.org/10.1016/j.paid.2013.12.012

Gouveia, V. V., Ribeiro, M. G. C., Loureto, G. D. L., Silva Neta, O. F., Gouveia, R. S. V., Vilar, R., \& Freire, S. E. A. (2019). Scale of positive and negative affects (EAPN-10): evidence of its psychometric adequacy. Trends Psychology, 27, 189- 203. doi: https://doi.org/10.9788/tp2019.1-14.

Jara, N., Casas, J. A., \& Ortega-Ruiz, R. (2017). Proactive and reactive aggressive behavior in bullying: the role of values. International Journal of Educational Psychology, 6, 1-24. doi: http://dx.doi.org/10.17583/ijep.2017.2515

Jebb, A. T., Morrison, M., Tay, L., \& Diener, E. (2020). Subjective well-being around the world: trends and predictors across the life span. Psychological Science, 31, 293-305. doi: https://doi.org/10.1177/0956797619898826

Karaca, S., Karakoc, A., Bingol, F., Eren, N., \& Andsoy, I. I. (2016). Comparison of subjective wellbeing and positive future expectations in between working and nonworking adolescents in turkey. Iranian Red Crescent Medical Journal, 18, e21055. doi: https://doi.org/10.5812/ircmj.21055

Mariano, T., Medeiros, E., Gouveia, V., Sales, H., \& Nascimento, A. (2018). Perfil Valorativo e Saúde Geral de Homens Usuários da Atenção Básica. Revista de Psicologia da IMED, 10, 108-124. doi:https://doi.org/10.18256/21755027.2018.v10i1.2593

Marques, C., Silva, A. D., \& do Céu Taveira, M. (2017). Valores como preditores da 
satisfação com a vida em jovens. Psico-USF, 22, 207-215. doi: https://doi.org/10.1590/1413-82712017220202

Massaroni, L., \& Barbosa, A. (2016). Convivendo com a morte e o morrer. Journal of Nursing UFPE, 10, 457-463. doi: https://doi.org/10.5205/1981-8963v10i2a10977p457-463-2016

Mondragon-Sanchez, E. J., Landeros-Olvera, E., \& Pérez-Noriega, E. (2020). Validación de la escala de miedo a la muerte de collett-lester en estudiantes universitarios de enfermería de México. MedUNAB, 23, 11-22. dói: https://doi.org/10.29375/01237047.3723

Morais, I. M. (2012). A escolha do lugar onde morrer por estudantes e médicos: valores humanos e percepção de morte digna. Tese de Doutorado. Universidade do Porto, Porto, Portugal.

Morais, I. M., Nunes, R., Cavalcanti, T., Soares, A. K. S., Gouveia, V. V. (2016). Percepção da "morte digna" por estudantes e médicos. Revista Bioética, 24, 108-17. doi: http://dx.doi.org/10.1590/1983-80422016241112

Oliveira-Júnior, C., Machado, D., Santos, F., da Silva, J., \& Domingues, E. (2018). Adaptação transcultural da Collett-Lester Fear of Death Scale à realidade brasileira. Revista Online de Pesquisa Cuidado é Fundamental. 10, 210-216. doi: http://dx.doi.org/10.9789/2175-5361.rpcfo.v10.5964

Omena, L. M., \& Funari, P. P. A. (2017). As experiências sociais da morte: diálogos interdisciplinares. Editora Paco: São Paulo.

Palgi, Y., Shrira, A., Ben-Ezra, M., Spalter, T., Shmotkin, D., \& Kavé, G. (2010). Delineating terminal change in subjective well-being and subjective health. Journal of Gerontology: Series B, 65, 61-64. doi: http://dx.doi.org/10.1093/geronb/gbp095

R Development Core Team (2011). R: A Language and Environment for Statistical Computing. R Foundation for Statistical Computing, Vienna, Austria. ISBN 3- 
900051-07-0, URL http: //www.R-project.org/.

Simkin, H., \& Quintero, S. (2017). Validación de la escala de miedo a la muerte abreviada al contexto argentino. \{PSOCIAL\}, 3, 53-59.

Wong, P., Reker, G., \& Gesser, G. (1994). Death attitude profile-revised: a multidimensional measure of attitudes toward death $\left(2^{\circ} \mathrm{Ed}.\right)$. Washington: Taylor \& Francis.

\section{Declaração do contributo dos autores}

AK e NC contribuíram para o desenho da revisão bibliográfica que define o referencial teórico, as bases de dados, as palavras-chave de busca e a forma de análise dos artigos selecionados. Da mesma forma, a redação e revisão final do manuscrito foram um trabalho conjunto de AK, NC, HM e AT.

\section{Editor de sección}

El editor de sección de este artículo fue Daniel Camparo Avila.

ORCID ID: 0000-0003-3440-5797

\section{Formato de citación}

Soares, A.K.S., Barbosa, N.C.S., Moura, H.M., \& Rezende, A.T. (2021). Percepção de medo da morte: avaliando sua relação com os valores humanos e bem-estar subjetivo. Psicología, Conocimiento y Sociedad, 11(1), 198-221. doi: http://dx.doi.org/10.26864/PCS.v11.n1.9 